\title{
Gait in normal pressure hydrocephalus: characteristics and effects of the CSF tap test
}

\author{
Marcha na hidrocefalia de pressão normal: características e efeitos do tap-test \\ Ricardo Krause Martinez de Souza', Samanta Fabrício Blattes da Rocha², Rodrigo Tomazini Martins ${ }^{3,4}$, \\ Pedro André Kowacs ${ }^{4}$, Ricardo Ramina ${ }^{5}$
}

\begin{abstract}
Normal pressure hydrocephalus (NPH), described by Hakim and Adams in 1965, is characterized by gait apraxia, urinary incontinence, and dementia. It is associated with normal cerebrospinal fluid (CSF) pressure and ventricular dilation that cannot be attributed to cerebral atrophy. Objectives: To evaluate gait characteristics in patients with idiopathic NPH and investigate the effect of the CSF tap test (CSF-TT) on gait. Methods: Twenty-five patients diagnosed with probable idiopathic NPH were submitted to the CSF-TT. The procedure aimed to achieve changes in gait parameters. Results: Fifteen gait parameters were assessed before and after the CSF-TT. Five showed a statistically significant improvement ( $p<0.05)$ : walking speed $(p<0.001)$, cadence $(p<0.001)$, step length $(p<0.001)$, en bloc turning ( $p=0.001)$, and step height $(p=0.004)$. Conclusion: This study demonstrated that gait speed was the most responsive parameter to the CSF-TT, followed by cadence, step length, en bloc turning, and step height.
\end{abstract}

Keywords: gait; normal pressure hydrocephalus.

RESUMO

A hidrocefalia de pressão normal (HPN), descrita por Hakim-Adams em 1965, caracteriza-se por apraxia de marcha, incontinência urinária e demência e está associada com pressão normal do líquido cefalorraquidiano e dilatação ventricular não atribuída a atrofia cerebral. Objetivos: Avaliar as características da marcha em pacientes com HPN idiopática e o efeito do "tap-test" (TT) na marcha. Métodos: Vinte e cinco pacientes com o diagnóstico HPN idiopática provável, foram avaliados com o TT. 0 procedimento tem como objetivo causar mudanças nas características da marcha. Resultados: Quinze parâmetros da marcha foram avaliados com o TT. Cinco mostraram melhora estatisticamente significativa ( $p<0,05)$ : velocidade da marcha $(p<0,001)$, cadência $(p<0,001)$, comprimento do passo ( $p<0,001)$, giro em "bloco" ( $p=0,001)$ e altura do passo ( $p=0,004)$. Conclusão: Este estudo demonstrou que a velocidade da marcha foi o parâmetro que mais respondeu ao efeito do TT, seguido da cadência, comprimento do passo, giro em "bloco" e altura do passo.

Palavras-chave: marcha; hidrocefalia de pressão normal.

Normal pressure hydrocephalus (NPH), described by Adams et al. ${ }^{1}$ in 1965 , is characterized by a classic triad of symptoms, consisting of progressive gait apraxia, urinary incontinence, and dementia. They are associated with normal cerebrospinal fluid (CSF) pressure and ventricular dilation that cannot be attributed to cerebral atrophy'.

A transient improvement in NPH symptoms following removal of CSF by lumbar puncture (LP) was first reported by Adams et al. ${ }^{1}$. However, Wikkelsø et al. ${ }^{2}$ refined the technique with quantitative methods to assess gait and cognition. The test has now gained widespread acceptance and is referred to as the CSF tap test (CSF-TT)2. The TT is important for diagnosing $\mathrm{NPH}^{3,4}$ as well as predicting clinical postoperative outcomes ${ }^{3,4}$. The volume of CSF removed can vary between 15 to $50 \mathrm{~mL}$, according to different authors ${ }^{5,6}$. According to Japanese guidelines, the CSF-TT should be the first invasive test indicated ${ }^{3}$ when NPH is suspected; it has a positive predictive value of between $72 \%$ and $100 \%$ and a low rate of complications? ${ }^{7}$.

Gait disturbance is considered the first and main symptom in $\mathrm{NPH}^{8,9}$. Close observance of any changes in gait is fundamental for early diagnosis of the disease, as this

\footnotetext{
'Instituto de Neurologia de Curitiba, Divisão de Demências e Outros Distúrbios Cognitivos e Comportamentais, Curitiba PR, Brasil;

${ }^{2}$ Instituto de Neurologia de Curitiba, Serviço de Neuropsicologia, Curitiba PR, Brasil;

${ }^{3}$ Box Hill Hospital (Eastern Health), Neurosciences Department, Melbourne VIC, Australia;

${ }^{4}$ Instituto de Neurologia de Curitiba, Departamento de Neurologia, Curitiba PR, Brasil;

${ }^{5}$ Instituto de Neurologia de Curitiba, Departamento de Neurocirurgia, Curitiba PR, Brasil.
}

Correspondence: Ricardo Krause Martinez de Souza; Rua Marechal Deodoro, 2152; 80045-235 Curitiba PR, Brasil; E-mail: ricardo.neurologia@gmail.com Conflicts of interest: There is no conflict of interest to declare.

Received 22 November 2017; Received in final form 01 February 2018; Accepted 14 February 2018. 
ensures a more favorable outcome for ventriculoperito-

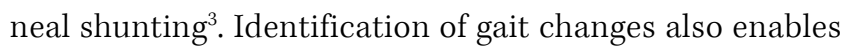
the CSF-TT to differentiate NPH from other diseases that mimic it. Correct diagnosis avoids unnecessary surgical procedures, including complications that may occur in up to $50 \%$ of patients ${ }^{10}$.

The aim of this study was to identify gait impairment and parameters that respond to the CSF-TT in patients with probable idiopathic NPH (INPH), according to diagnostic criteria in the American-European INPH guidelines ${ }^{4}$.

\section{METHODS}

We prospectively evaluated 97 patients with suspected $\mathrm{NPH}$ at the Curitiba Institute of Neurology from January 2006 to January 2011. Informed consent was obtained from all patients, and the study was approved by the local regulatory board.

Criteria for INPH diagnosis are those from the American-European guidelines, which classifies INPH into "probable", "possible", and "unlikely" ${ }^{4}$ Of 97 patients selected, 72 were excluded from the study and 25 met the inclusion criteria, characterizing our sample (Figure 1).

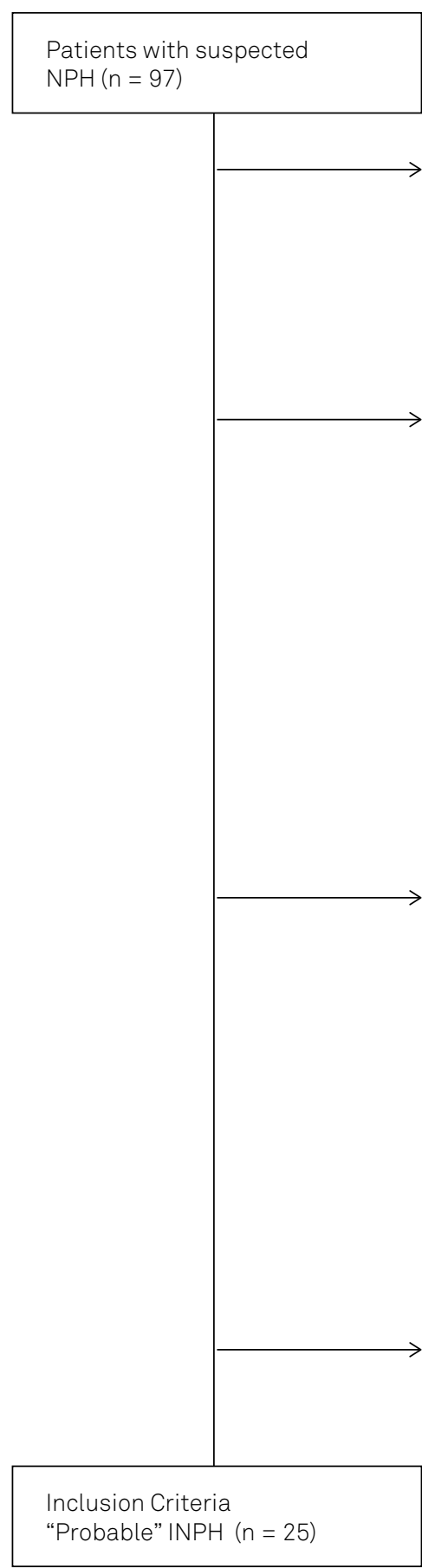

Exclusion: various etiologies $(n=5)$

1 - Unable to walk (dyspnea on minimal exertion)

2 - Unable to walk (severe gait apraxia)

1 - Thrombocytopenia (<50.000)

1 - Refusal by the patient (technical difficulty for lumbar puncture)

Exclusion: secondary hydrocephalus $(n=15)$

3 - Post neurosurgery

1 - Post neurosurgery (epilepsy)

3 - Head trauma

1 - Obstruction of the third ventricle

1 - Colloid cyst of the third ventricle

3 - Infection: (HIV, neurocysticercosis, syphilis)

1 - Glial neoplasia

2 - Longstanding overt ventriculomegaly in adults

Exclusion: INPH "possible" $(n=38)$

1 - Treated neurosyphilis

1 - Polyneuropathy

1 - Lumbar spinal stenosis

1 - Motor neuron disease

1 - Subarachnoid hemorrhage (remote history)

1 - Vitamin B12 deficiency

1 - Opening pressure $260 \mathrm{mmH}_{2} \mathrm{O}$ (no signs of intracranial hypertension)

1 - Psychiatric disorder

2 - Mild traumatic brain injury

5 - Atypical parkinsonism (some features)

2 - Parkinson's disease (some features)

9 - Vascular dementias (some features)

12- Alzheimer's disease (some features)

Exclusion: INPH "Unlikely" ( $n=14)$

2 - Asymptomatic ventriculomegaly with features of INPH on MRI

4 - Alzheimer's disease

1 - Parkinson's disease

1 - Progressive supranuclear palsy

2 - Microvascular frontal-subcortical syndrome of aging

1 - Psychiatric disorder (paraphrenia)

1 - Alcohol-related dementia

2 - Vascular dementia

INPH: idiopathic normal pressure hydrocephalus; HIV: human immunodeficiency virus.

Figure 1. Patients with suspicion of normal pressure hydrocephalus: inclusion and exclusion criteria. 
The inclusion criteria were based on proposed guidelines for the diagnosis of probable INPH according to Relkin et al. ${ }^{4}: 1$ ) insidious onset of symptoms after 40 years of age, with a duration longer than six months, and progression over time; 2) slow progressive gait dysfunction; 3) and the gait/balance disorder must be present, plus one other area of impairment in cognition, urinary symptoms, or both. Cognitive impairment was screened using the Mini-Mental State Examination test, adapted to our environment and adjusted for the educational level of the population ${ }^{11}$. The criteria to diagnose dementia were from the Diagnosis and Statistics Manual of Mental Disorders ${ }^{12}$; 4) urinary incontinence not attributed to primary urological disorders; 5) ventricular dilatation demonstrated by CT scan or MRI of the brain, not entirely attributable to cerebral atrophy or congenital enlargement (Evan's index > 0.3); and 6) normal CSF opening pressure in the range $70-245 \mathrm{mmH}_{2} \mathrm{O}$ determined by LP.

Exclusion criteria were: 1) a diagnosis of possible and unlikely INPH ${ }^{10}$; 2) secondary hydrocephalus, as a consequence of head trauma, intracerebral hemorrhage, and meningitis/encephalitis; 3) serious clinical or laboratory contraindication for the procedure (blood dyscrasias not amenable to correction); 4) brain imaging findings associated with any of the following: ventricular dilatation caused by macroscopic obstruction to CSF flow, and evidence of severe cerebral atrophy (score 3) sufficient potentially to cause ventricular enlargement. Simple rating scales were used to quantify the degree of global cortical atrophy. The four-step scale ${ }^{13}$ classifies cerebral atrophy from score $0=$ no atrophy to score $3=$ severe atrophy, or the presence of structural lesions that may impact ventricular size, such as gliosis secondary to stroke and/or the presence of extensive vascular white matter lesions (Fazekas grade 3). The Fazekas scale $^{13}$ quantifies cerebral white matter lesions and how they develop over time. The scale ranges from 0 to 3 , where $0=$ no lesions or a single punctate lesion, $1=$ multiple punctate lesions, 2 = confluent lesions, and $3=$ extensive confluent lesions; 5) the patient is unable to walk or is severely demented and incapable of understanding the commands required to do a certain task; 6) musculoskeletal disorders that could interfere with gait analysis, such as rheumatoid arthritis or polyneuropathy; 7) chronic obstructive pulmonary disease and/or heart failure with dyspnea on minimal exertion; and 8) other causes of dementia.

\section{Tap test}

The test involved removal of CSF with a disposable Quincke needle for LP to gauge gait changes (clinical improvement). On the first day of the test, the patients were assessed for their baseline gait (Figure 2). On two consecutive days, LP was performed with an interval of 24 hours between procedures. Patients were in a lateral recumbent position during the LP and while the opening pressure was measured. A total of $30 \mathrm{~mL}$ of CSF was removed during each LP. The CSF collected was sent to the onsite clinical laboratory for analysis. Three hours after the LP, the patient's gait was recorded to determine whether the TT had resulted in any improvement.

\section{Gait analysis}

Gait characteristics were assessed during free walking on a 10 meter $(\mathrm{m})$ predesigned path. The study consisted of filming the patient walking on a $20 \mathrm{~m}$ path $(10 \mathrm{~m}$ in one direction, turning, and then $10 \mathrm{~m}$ back to the starting point) during two trials, totaling $40 \mathrm{~m}$ of free walking (Figure 2). Gait velocity and step length were calculated as the mean values during the two trials. Patients were asked to walk and were also given these instructions: "follow this path", "go to the location indicated", "turn around", and then "return to the starting point" and "walk as fast as you can, with no running" (Figure 2). Tests were always carried out during the early afternoon to avoid possible time-related fluctuations.

Patients were filmed while walking, and data were transferred to a desktop computer, so that gait and posture could be analyzed. This was always done by two physicians (the first author and another member of the medical staff in the neurology department). Criteria used to evaluate gait and posture $4,14,15,16,17,18,19,20$ are described in Table 1. The patient's gait speed was considered reduced when the time spent to traverse $10 \mathrm{~m}$ was greater than 11 seconds (s). ${ }^{21}$ Stolze et al. ${ }^{19}$ adopted a result greater than $20 \%$ as indicative of an improvement in gait velocity, while Damasceno et al. ${ }^{8}$ considered an improvement as any result greater than $5 \%$. In our study, an intermediate value was adopted. An improvement greater than 9\% after the CSF-TT was considered the cut-off value for a gain in gait velocity. The following formula was used in percentages to evaluate if there was improvement in gait speed with the TT: $100 \mathrm{X}$ (result before LP - best result after LP) / result before $\mathrm{LP}^{14}$.

\section{Statistical analysis}

The results are expressed as means $\pm \mathrm{SD}$, or frequencies and percentages when appropriate. The results were analyzed using the Statistical Package for the Social Sciences, version 22.0 (Armonk, NY, USA). Each of the gait variables (gait speed, broad-based gait, en bloc gait, decreased step length, lateral flexion of the trunk, postural reflex, festination, hesitant gait, en bloc turning, imbalance, freezing, decreased cadence, trunk flexion, and toes turned outwards on walking) were classified qualitatively as "changed" or "unchanged" based on the evaluation of the researchers during the pre- and post-CSF-TT period. The McNemar Test was used for the analysis of these variables. The Wilcoxon test, a non-parametric test, evaluated the quantitative results obtained before and after the CSF-TT, and the time taken to traverse the $20 \mathrm{~m}$ path. Values of $\mathrm{p}<$ 0.05 were considered significant. 


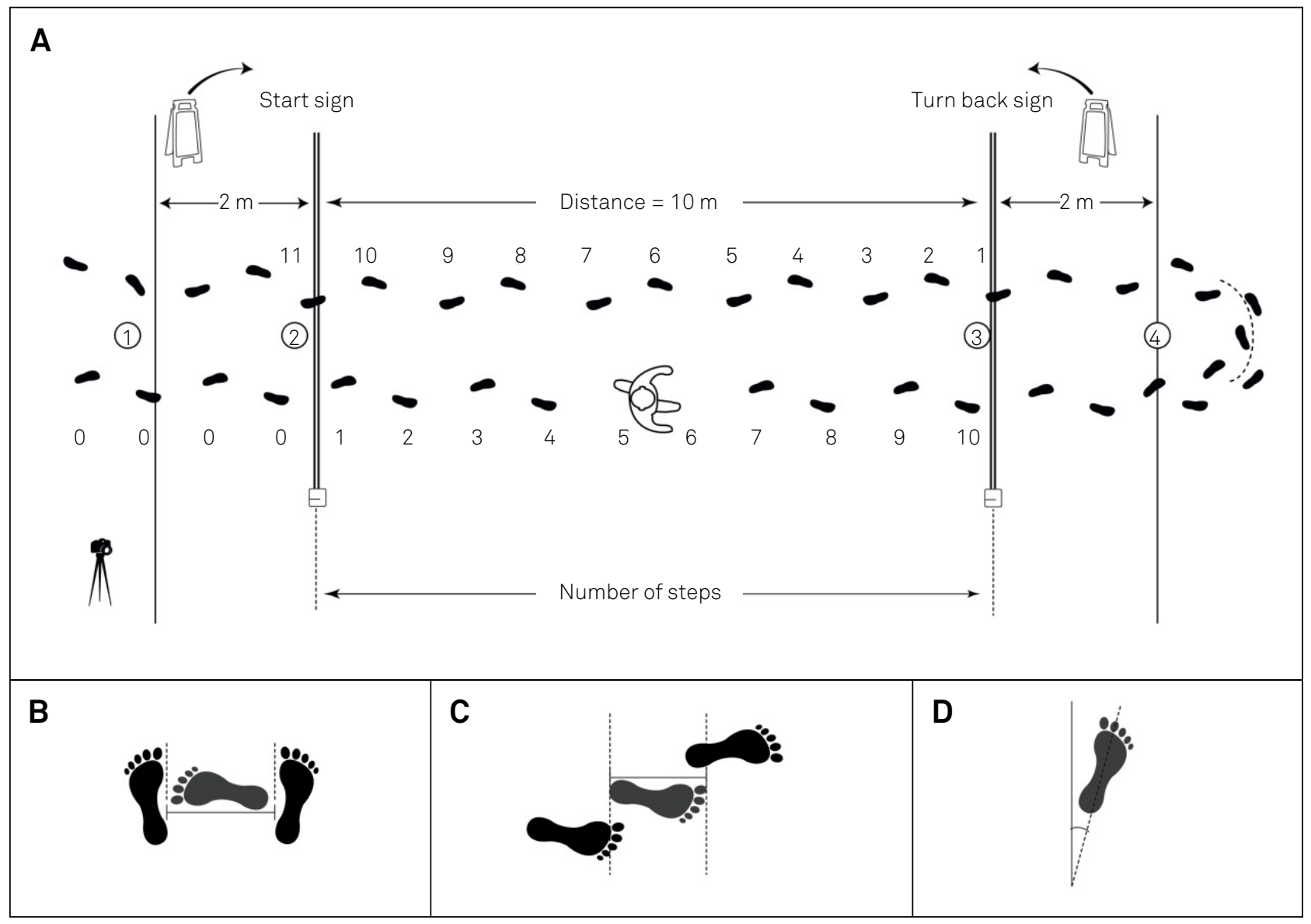

Source: Authors.

Figure 2. (A) Schematic viewed from above for the evaluation of gait parameters in patients with IHPN, (B) broad-based gait, (C) decreased step length, (D) toes turned outward.

\section{RESULTS}

The mean age of the cohort was 76.2 years (range 65-84 years, $\mathrm{SD}=5.8$ ) with 10 males and 15 females; all were right-handed; two were Afro-Brazilian and 23 were Caucasian. Three patients were illiterate and 22 had a formal education. The latter were divided into four groups according to the length of their formal education: eleven patients (1-4 years); two patients (4-8 years), two patients (9-11 years); and seven patients (> 11 years).

\section{General sample characteristics}

The term gait apraxia was defined to describe the features of a frontal gait disturbance such as: disequilibrium, impaired postural reflexes, and gait ignition with start hesitation, which could not be attributed to any motor, sensory, or psychiatric deficits ${ }^{20}$. The complete triad described by Adams et al. ${ }^{1}$ was present in 22 of our patients (88\%). Gait disturbance and dementia were detected in all patients; however, three had no urinary incontinence. A gait matching the classic description of "gait apraxia" was found only in four patients.

The average time between onset of symptoms of INPH and the CSF-TT was 22.9 months (range 3-60 months, SD = 13.2).
On neurological examination, dysarthria and supranuclear vertical upgaze palsy were observed in three patients, while frontal release signs were observed in five. The mean score on the Mini-Mental State Examination was 22.3 (SD = 5.2). The most commonly-associated condition was arterial hypertension in 20 patients $(80 \%)$, followed by 11 patients with dyslipidemia (44\%), 10 patients with diabetes mellitus (40\%), seven with psychiatric diseases (28\%) (anxiety in one and depression in six), five patients with hypothyroidism (20\%), three patients with cardiac diseases (12\%), one with hyperuricemia and one smoker (4\%).

\section{Gait features}

Fifteen gait variables were studied (Table 2 and Figure 3), and abnormalities were found in 14 of them. A festinating gait was not observed in any of the patients. Of the 25 patients evaluated, 19 improved more than $9 \%$ in walking time with the CSF-TT. Only one patient had a gait within normal values, but there was improvement of more than $9 \%$ after the CSF-TT. The average time taken to traverse the $20 \mathrm{~m}$ path was $45.3 \mathrm{~s}$ pre-CSFTT vs. $35.2 \mathrm{~s}$ post-CSF-TT, corresponding to an improvement of approximately $10 \mathrm{~s}(28.7 \%)$ post-CSF-TT $(\mathrm{p}<0.05)$. Gait variables responsive to the CSF-TT are shown in Table 2 and Figure 3. 
Table 1. Classification of gait and posture 4,14,15,16,17,18,19,20.

\begin{tabular}{|c|c|c|}
\hline Parameters & \multicolumn{2}{|c|}{ Description } \\
\hline En bloc turning & \multicolumn{2}{|c|}{ Requiring three or more steps for turning 180 degrees. } \\
\hline Dynamic balance or imbalance & \multicolumn{2}{|c|}{$\begin{array}{l}\text { Patient is asked to walk } 8 \text { steps putting one foot in front of the other (tandem gait). Imbalance was } \\
\text { considered to be present when correction steps were needed on two or more attempts. }\end{array}$} \\
\hline En bloc gait & \multicolumn{2}{|c|}{ Reduced rotation of the pelvic and scapular girdles and decreased mobility of the upper limbs. } \\
\hline Festination & \multicolumn{2}{|c|}{ Accelerated gait at least once in the total path. } \\
\hline \multirow[t]{6}{*}{ *Postural Reflex } & Score & g test \\
\hline & Patient stand & it taking a step \\
\hline & Patient takes a & d remains stable \\
\hline & Patient takes more than c & and keeps his/her balance \\
\hline & Patient takes sever & and needs to be held \\
\hline & Patient falls back & thout taking a step \\
\hline Freezing & \multicolumn{2}{|c|}{$\begin{array}{c}\text { Characterized by at least one episode of sudden deceleration or a break (feet almost stuck to floor) } \\
\text { in gait during free walking. }\end{array}$} \\
\hline Hesitant gait & \multicolumn{2}{|c|}{ Hesitation at the beginning and end of the course. } \\
\hline "Magnetism" or shuffling gait & \multicolumn{2}{|c|}{ Step height decreased during free walking. } \\
\hline Broad-based gait & \multicolumn{2}{|c|}{ Distance between toes > 1 own foot length. (Figure 2 B) } \\
\hline Decreased step length (petit pas) & \multicolumn{2}{|c|}{ Distance from heel of front foot to toes of rear foot < 1 own foot length. (Figure $2 \mathrm{C}$ ) } \\
\hline Foot angle & \multicolumn{2}{|c|}{ Toes turned outward on walking. (Figure 2 D) } \\
\hline Trunk flexion & \multicolumn{2}{|c|}{ A healthy person remains standing upright with his/her head up, chest out and abdomen held in. } \\
\hline Lateral flexion of the trunk & \multicolumn{2}{|c|}{ Flexion of the trunk to one side while walking spontaneously. } \\
\hline \multirow{3}{*}{$\begin{array}{l}\text { Gait cadence (Reference value for } \\
\text { normality) }\end{array}$} & Age: $60-69$ years & Age: $70-79$ years \\
\hline & 148 steps per minute $(S D \pm 23.07)$ & 129.5 steps per minute $(S D \pm 21.79)$ \\
\hline & $* \star$ Not given & 119.4 steps per minute $(S D \pm 11.07)$ \\
\hline
\end{tabular}

Table 2. Evaluation of gait characteristics before and after the tap test.

\begin{tabular}{|c|c|c|c|c|c|c|c|c|c|}
\hline \multirow{2}{*}{$\begin{array}{l}\text { Before TT / After TT } \\
\text { Characteristics Gait }\end{array}$} & \multicolumn{2}{|c|}{$\begin{array}{l}\text { Unchanged / } \\
\text { Unchanged }\end{array}$} & \multicolumn{2}{|c|}{ Changed / Changed } & \multicolumn{2}{|c|}{ Changed / Unchanged } & \multicolumn{2}{|c|}{$\begin{array}{l}\text { Unchanged / } \\
\text { Changed }\end{array}$} & \multirow[t]{2}{*}{$p$-value* } \\
\hline & Freq. & $\%$ & Freq. & $\%$ & Freq. & $\%$ & Freq. & $\%$ & \\
\hline Speed gait & 0 & 0 & 6 & 24 & 19 & 76 & 0 & 0 & $<0.01$ \\
\hline Broad-based & 14 & 56 & 8 & 32 & 2 & 8 & 1 & 4 & 1.0 \\
\hline En bloc gait & 11 & 44 & 9 & 36 & 5 & 20 & 0 & 0 & 0.063 \\
\hline Decreased step length & 6 & 24 & 7 & 28 & 12 & 48 & 0 & 0 & $<0.01$ \\
\hline Decreased step height & 6 & 24 & 10 & 40 & 9 & 36 & 0 & 0 & $<0.01$ \\
\hline Lateral flexion of the trunk & 19 & 76 & 5 & 20 & 1 & 4 & 0 & 0 & 1.0 \\
\hline Postural reflex & 22 & 88 & 3 & 12 & 0 & 0 & 0 & 0 & 1.0 \\
\hline Festination & 25 & 100 & & & & & & & - \\
\hline Hesitant gait & 21 & 84 & 2 & 8 & 2 & 8 & 0 & 0 & 0.50 \\
\hline En bloc turning & 6 & 24 & 8 & 32 & 11 & 44 & 0 & 0 & $<0.01$ \\
\hline Imbalance & 17 & 68 & 7 & 28 & 1 & 4 & 0 & 0 & 1.0 \\
\hline Freezing & 24 & 96 & 0 & 0 & 1 & 4 & 0 & 0 & 1.0 \\
\hline Decreased cadence & 5 & 20 & 8 & 32 & 12 & 48 & 0 & 0 & $<0.01$ \\
\hline Trunk flexion & 20 & 80 & 4 & 16 & 1 & 4 & 0 & 0 & 1.0 \\
\hline Toes turned outward on walking & 19 & 76 & 5 & 20 & 1 & 4 & 0 & 0 & 1.0 \\
\hline
\end{tabular}

* McNemar test, $p<0.05$

\section{DISCUSSION}

In this study, the classic triad of INPH was found in $88 \%$ of patients. The incidence of the classical triad is unknown; however, the presence of three concomitant symptoms has been reported in approximately $60 \%$ of cases ${ }^{3}$, although the triad is not required for a diagnosis of $\mathrm{INPH}^{3}$.

Ishii et al. ${ }^{22}$ and Kang et al. ${ }^{23}$ reported that the presence of parkinsonism characteristics was frequent in patients with INPN. However, consistent with findings from another 


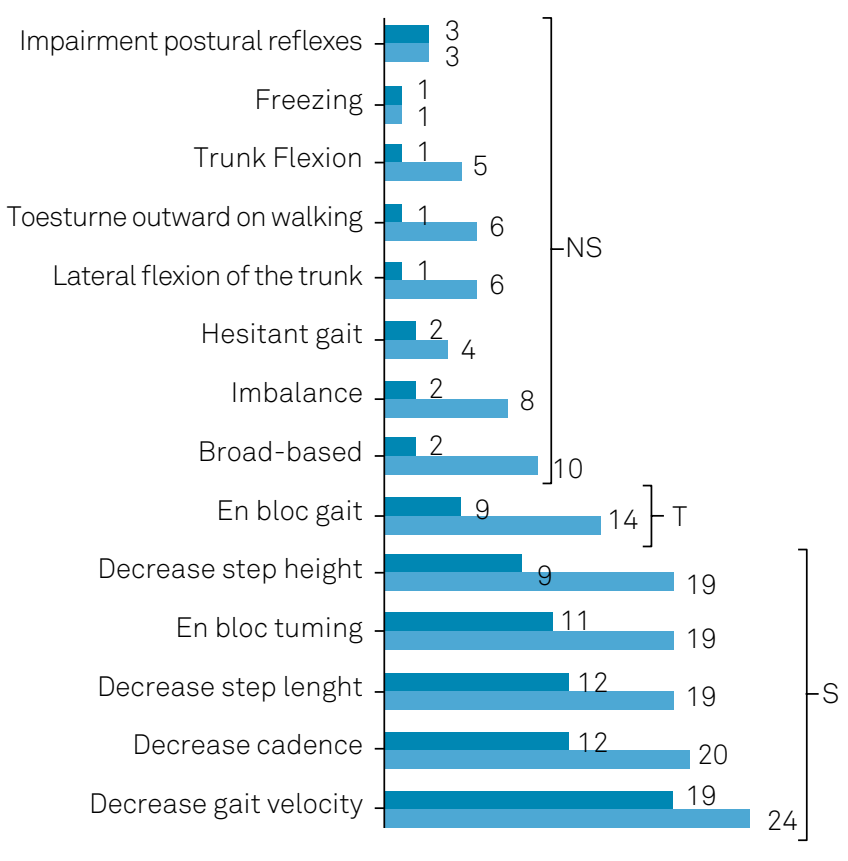

After TT Before TT

TT: tap test; $\}$ : the graphic signal expresses the statistical result with the effect of the TT; NS: not statistically significant; T: trend; S: statistically significant.

Figure 3. Evaluation of gait characteristics before and after the tap test based on results shown in Table 2.

study $^{14}$, our results indicate that parkinsonian signs are unusual. A possible explanation for these different outcomes was that the aforementioned authors did not discuss whether patients with "probable" and "possible" INPH were included in their criteria. Due to the inclusion of "possible" patients, those with atypical parkinsonism may have been included in the cohort. We included only "probable" patients, similar to the Bugalho and Guimarães study ${ }^{14}$. On the other hand, in the present study, specific scales to assess parkinsonism, such as the Unified Parkinson's Disease Rating Scale, were not used.

Gait disturbance in INPH is classically described as slow and broad-based, which is associated with imbalance (tandem gait) and en bloc turning ${ }^{24}$. Stolze et al. ${ }^{19}$ also described, magnetic gait, and broad-based gait. Another study demonstrated that slowness, loss of balance, and short stride were the most frequent features in NPH patients ${ }^{14}$. The gait pattern triad characteristic in INPH consists of a small-stepped gait, magnetic gait, and broad-based gait ${ }^{3}$. In our patients with INPH, the main gait disturbances included velocity, cadence, step height, step length, en bloc turning, and en bloc gait, present in approximately $80 \%$ of patients. Ten patients (40\%) had a broad-based gait, while eight patients (32\%) had imbalance. Jankovic et al. ${ }^{16}$ classified gait dysfunction in frontal gait and subcortical hypokinetic gait. Frontal gait dysfunction was characterized by decreased step length and height, imbalance, leg apraxia, freezing, abnormal stance (broad-based > narrow base), abnormal postural reflex, trunk/leg stiffness and frontal release signs, whereas the subcortical hypokinetic gait dysfunction presented with decreased step length and height, festination, start hesitation, freezing, en bloc turning, narrow base, abnormal postural reflex, shuffling, and parkinsonian signs. Gait disturbances observed in our patients with INPH suggest involvement of systems that modulate the cortical and subcortical regions, according to the classific

Gait velocity was found to be the feature that improved the most with CSF removal. Similarly, other studies have also shown gait speed to be the parameter most sensitive to the CSF-TT ${ }^{5,6,14}$. Measuring gait velocity requires only a stopwatch and no other specific or costly equipment ${ }^{6}$. In addition to improving gait velocity with the CSF-TT, cadence, step length, en bloc turning, and step height were the features most affected by the CSF-TT. The en bloc gait showed a marginal improvement after the CSF-TT, a trend that perhaps could become significant if studied in a larger cohort.

Surprisingly, in the present study, cadence was the second parameter most altered, showing a significant improvement after the CSF-TT. However, the results of several studies are less consistent regarding cadence, which was found to be unchanged ${ }^{6,19}$ or higher ${ }^{25}$ with the effects of the CSF-TT.

En bloc gait was present in 14 patients, and improved in 9 cases after the TT. Typical en bloc gait was also observed, and it is believed to act as a compensatory mechanism to reduce a lack of gait balance ${ }^{26}$. In other words, the decrease in mobility of the pelvic and scapular girdles and of the upper limbs occurs to avoid displacement of the gravity center and to maintain a safe balance during gait. The improvement in gait speed (step length and increased height) and en bloc turning suggests an improvement in functions related to the anatomy of subcortical regions. These findings support the hypothesis of secondary involvement of subcortical circuits in INPH and the hypothesis that impairment of these structures can be reversed by removing CSF, corroborating the findings of Mocco et al. ${ }^{27}$. No statistically significant improvement in other gait variables was observed following the CSF-TT. According to some authors, imbalance is a feature that does not improve after a CSF-TT ${ }^{5,19}$. This was supported by our own findings, as no improvement in balance was observed. Ravdin et al. ${ }^{5}$ found that trunk balance (en bloc gait) showed a trend towards improvement, similar to our study.

We found outward rotation of the feet in 6 patients (24\%) and a broad-based gait in 10 patients (40\%), which is a less common feature of idiopathic Parkinson's disease ${ }^{19}$. These findings can assist in the differential diagnosis of $\mathrm{INPH}^{19}$. However, another study reported that gait in Parkinson's disease and NPH are similar; therefore, it is not possible to differentiate between both, based solely on gait pattern ${ }^{25}$.

Yamada et al. ${ }^{28}$ observed that patients with the shortest disease course had a better response to CSF-TT. In our work, the duration of the disease showed no relation to the response to the CSF-TT. The results of the present study, which used semi-quantitative visual analysis of posture and gait parameters, did not differ significantly from those of other studies in the literature that used quantitative analysis ${ }^{6,19}$. This type 
of gait analysis, with infrared markers, requires expensive equipment and a specific location where the assessment can be conducted (i.e., gait laboratory) and, therefore, is not easily affordable. The semi-quantitative approach in this study proved to be effective in identifying gait characteristics and any changes in these after CSF removal; it also had the advantage of being more affordable. However, it requires the presence of an experienced neurologist to recognize subtle changes in NPH.

The complication rate of the test in our series was very low. The only complication observed after removal of
CSF was not serious (headache) and occurred in only one patient (4\%). A similar complication rate was reported by Malm et al. ${ }^{7}$. Thus, the CSF-TT can be considered safe and, as stated, should be the first invasive test indicated when INPH is suspected ${ }^{3}$. The main limitation of the study was the small sample size, due to the strict exclusion criteria.

In short, this study demonstrated that gait speed is the most sensitive parameter assessed after CSF-TT, followed by cadence, step length, en bloc turning, and step height. Further investigation is warranted to gauge changes in gait speed after ventriculoperitoneal shunting.

\section{References}

1. Adams RD, Fisher CM, Hakim S, Ojemann RG,

Sweet WH. Symptomatic occult hydrocephalus with

"normal" cerebrospinal-fluid pressure: a treatable syndrome. N Engl J Med. 1965 Jul;273(3):117-26. https://doi.org/10.1056/NEJM196507152730301

2. Wikkels $\varnothing \mathrm{C}$, Andersson $\mathrm{H}$, Blomstrand C, Lindqvist $\mathrm{G}$. The clinical effect of lumbar puncture in normal pressure hydrocephalus. J Neurol Neurosurg Psychiatry. 1982 Jan;45(1):64-9. https://doi.org/10.1136/jnnp.45.1.64

3. Mori E, Ishikawa M, Kato T, Kazui H, Miyake H, Miyajima M et al. Guidelines for management of idiopathic normal pressure hydrocephalus: second edition. Neurol Med Chir (Tokyo). 2012;52(11):775-809. https://doi.org/10.2176/nmc.52.775

4. Relkin N, Marmarou A, Klinge P, Bergsneider M, Black PM. Diagnosing idiopathic normal-pressure hydrocephalus [discussion ii-v.]. Neurosurgery. 2005 Sep;57(3 Suppl):S4-16. https://doi.org/10.1227/01.NEU.0000168185.29659.C5

5. Ravdin LD, Katzen HL, Jackson AE, Tsakanikas D, Assuras S, Relkin NR. Features of gait most responsive to tap test in normal pressure hydrocephalus. Clin Neurol Neurosurg. 2008 May;110(5):455-61. https://doi.org/10.1016/j.clineuro.2008.02.003

6. Stolze H, Kuhtz-Buschbeck JP, Drucke H, Johnk K, Diercks $\mathrm{C}$, Palmie $\mathrm{S}$ et al. Gait analysis in idiopathic normal pressure hydrocephalus-which parameters respond to the CSF tap test? Clin Neurophysiol. 2000 Sep;111(9):1678-86. https://doi.org/10.1016/S1388-2457(00)00362-X

7. Malm J, Kristensen B, Karlsson T, Fagerlund M, Elfverson J, Ekstedt J. The predictive value of cerebrospinal fluid dynamic tests in patients with th idiopathic adult hydrocephalus syndrome. Arch Neurol. 1995 Aug;52(8):783-9. https://doi.org/10.1001/archneur.1995.00540320059013

8. Damasceno BP, Carelli EF, Honorato DC, Facure JJ. The predictive value of cerebrospinal fluid tap-test in normal pressure hydrocephalus. Arq Neuropsiquiatr. 1997 Jun;55(2):179-85. https://doi.org/10.1590/S0004-282X1997000200003

9. Fisher CM. Hydrocephalus as a cause of disturbances of gait in the elderly. Neurology. 1982 Dec;32(12):1358-63. https://doi.org/10.1212/WNL.32.12.1358

10. Tisell M, Tullberg M, Hellström P, Edsbagge M, Högfeldt M, Wikkelsö C. Shunt surgery in patients with hydrocephalus and white matter changes. J Neurosurg. 2011 May;114(5):1432-8. https://doi.org/10.3171/2010.11.JNS10967

11. Brucki SM, Nitrini R, Caramelli P, Bertolucci PH, Okamoto IH. [Suggestions for utilization of the mini-mental state examination in Brazil]. Arq Neuropsiquiatr. 2003 Sep;61(3B):777-81. https://doi.org/10.1590/S0004-282X2003000500014
12. American Psychiatric Association. Diagnostic and statistical manual of mental disorders DSM-IV. 4th ed. Washington, DC: American Psychiatric Press; 1994.

13. Barkhof F, Fox NC, Bastos-Leite AJ, Scheltens P. Neuroimaging in dementia. Berlin: Springer-Verlag; 2001.

14. Bugalho P, Guimarães J. Gait disturbance in normal pressure hydrocephalus: a clinical study. Parkinsonism Relat Disord. 2007 Oct;13(7):434-7. https://doi.org/10.1016/j. parkreldis.2006.08.007

15. Castro CL, Santos JA, Leifeld PS, Bizzo LV, Silva LC, Almeida TF et al. Estudo da marcha em idosos: resultados preliminares. Acta Fisiatrica. 2000;7(3):103-7.

16. Jankovic J, Nutt JG, Sudarsky L. Classification, diagnosis, and etiology of gait disorders. Adv Neurol. 2001;87:119-33.

17. Kiefer M, Unterberg A. The differential diagnosis and treatment of normal-pressure hydrocephalus. Dtsch Arztebl Int. 2012 Jan;109(1-2):15-25. https://doi.org/10.3238/arztebl.2012.0015

18. Mashimo AM, Caromano FA. A marcha em idosos saudáveis. Arq Cienc Saúde. 2002;6(2):117-21. https://doi.org/10.25110/arqsaude.v6i2.2002.1166

19. Stolze H, Kuhtz-Buschbeck JP, Drücke H, Jöhnk K, Illert $\mathrm{M}$, Deuschl G. Comparative analysis of the gait disorder of normal pressure hydrocephalus and Parkinson's disease. J Neurol Neurosurg Psychiatry. 2001 Mar;70(3):289-97. https://doi.org/10.1136/jnnp.70.3.289

20. Thompson PD. Frontal lobe ataxia. Handb Clin Neurol. 2012;103:619-22. https://doi.org/10.1016/B978-0-444-51892-7.00044-9

21. Oberg T, Karsznia A, Oberg K. Basic gait parameters: reference data for normal subjects, 10-79 years of age. J Rehabil Res Dev. 1993;30(2):210-23.

22. Ishii M, Kawamata T, Akiguchi I, Yagi H, Watanabe Y, Watanabe T et al. Parkinsonian symptomatology may correlate with CT findings before and after shunting in idiopathic normal pressure hydrocephalus. Parkinson's disease. 2010;2010:201089. https://doi.org/10.4061/2010/201089

23. Kang K, Jeon JS, Kim T, Choi D, Ko PW, Hwang SK et al. Asymmetric and upper body parkinsonism in patients with idiopathic normal-pressure hydrocephalus. J Clin Neurol. 2016 Oct;12(4):452-9. https://doi.org/10.3988/jcn.2016.12.4.452

24. Gallia GL, Rigamonti D, Williams MA. The diagnosis and treatment of idiopathic normal pressure hydrocephalus. Nat Clin Pract Neurol. 2006 Jul;2(7):375-81. https://doi.org/10.1038/ncpneuro0237

25. Bugalho P, Alves L, Miguel R. Gait dysfunction in Parkinson's disease and normal pressure hydrocephalus: a comparative study. J Neural Transm (Vienna). 2013;120(8):1201-7. https://doi.org/10.1007/s00702-013-0975-3 
26. Pastor MA, Day BL, Marsden CD. Vestibular induced postural responses in Parkinson's disease. Brain. 1993 Oct;116(Pt 5):1177-90. https://doi.org/10.1093/brain/116.5.1177

27. Mocco J, Tomey MI, Komotar RJ, Mack WJ, Frucht SJ, Goodman RR et al. Ventriculoperitoneal shunting of idiopathic normal pressure hydrocephalus increases midbrain size: a potential mechanism for gait improvement. Neurosurgery. 2006 Oct;59(4):847-51. https://doi.org/10.1227/01.NEU.0000232655.78335.D5

28. Yamada S, Ishikawa M, Miyajima M, Atsuchi M, Kimura T, Kazui $\mathrm{H}$ et al. Disease duration: the key to accurate CSF tap test in iNPH. Acta Neurol Scand. 2017 Feb;135(2):189-96. https://doi.org/10.1111/ane.12580 